\title{
Exogenous Cushing's Syndrome with Subsequent Secondary Adrenal Insufficiency in Patients with Long Term Steroid Usage
}

\author{
Cynthia Ayu Permatasari' ${ }^{1}$, Ferdy Royland Marpaung ${ }^{2}$ \\ ${ }^{1}$ Resident, Clinical Pathology Specialty Medicine Program, Faculty of Medicine, Airlangga University-RSUD \\ Dr. Soetomo, Surabaya, Indonesia, ${ }^{2}$ Lecturer, Clinical Pathology Department, Faculty of Medicine, Airlangga \\ University-RSUD Dr. Soetomo, Surabaya, Indonesia
}

\begin{abstract}
Exogenous Cushing's syndrome is a collection of symptoms and clinical signs due to elevated levels of glucocorticoids (cortisol) in the blood because of prolonged consumption of glucocorticoid drugs. Glucocorticoids were introduced in the 1950s and have been used for anti-inflammatory treatment. Withdrawal of glucocorticoids can lead to complications of secondary adrenal insufficiency caused by suppression of the Hypothalamic-Pituitary-Adrenal (HPA) axis. Male, 28 years old, with weakness in both hands and feet throughout 3 days before admission to hospital. Other complaints include nausea $(+)$, vomiting $(+)$, diarrhea $(-)$. He had been taking dexamethasone daily in the past 3 years until one month ago when he suddenly stopped. Physical examination revealed moon facies $(+)$, striae $(+)$ in the abdomen, and motor strength of 2 in all four extremities. Laboratory: K $2.0 \mathrm{mmol} / \mathrm{L}, \mathrm{Mg} 0.8 \mathrm{mg} / \mathrm{dL}$, GDA $64 \mathrm{mg} / \mathrm{dL}$, Total cholesterol $240 \mathrm{mg} /$ $\mathrm{dL}$, cortisol $18.67 \mathrm{ng} / \mathrm{mL}, \mathrm{ACTH} 2.1 \mathrm{pg} / \mathrm{mL}$. The patient was diagnosed with exogenous Cushing's syndrome based on a history of long-term use of dexamethasone. Physical examination revealed moon face, buffalo hump, purplish striae, and hypertension. The patient stopped dexamethasone consumption suddenly and is consequently experiencing secondary adrenal insufficiency at the present time. As evidenced by laboratory values, there was a decrease in serum cortisol $(18.67 \mathrm{ng} / \mathrm{mL})$, as well as a decrease in serum ACTH (2.1 pg/ $\mathrm{mL}$ ). Based on the history of dexamethasone use, physical examination, and laboratory results, this patient had exogenous Cushing's syndrome. Sudden discontinuation of dexamethasone results in withdrawal symptoms in the form of secondary adrenal insufficiency as indicated by low cortisol and ACTH values.
\end{abstract}

Keywords: Cushing's syndrome, glucocorticoid, withdrawal, adrenal insufficiency.

\section{Introduction}

Cushing's syndrome is a term used to describe conditions resulting from increased concentrations of glucocorticoids (cortisol) in the blood circulation. The incidence of Cushing's syndrome is $0.7-2.4: 1,000,000$ population per year. This condition can be caused

\section{Corresponding Author:}

\section{Ferdy Royland Marpaung}

Lecturer, Clinical Pathology Department, Faculty of Medicine, Airlangga University-RSUD Dr. Soetomo, Surabaya, Indonesia

e-mail: ferdyoke@gmail.com by factors outside (exogenous) or inside the body (endogenous) ${ }^{1}$. Corticosteroid use is the most common cause of Cushing's syndrome, the exogenous type of which depends on the dose and potency of the steroid used and the duration of usage ${ }^{1-3}$.

Glucocorticoids were introduced in the 1950s, and have been used for anti-inflammatory, autoimmune and neoplastic treatment. Cushing's syndrome can manifest as a result of Glucocorticoids usage for treatment over a long period of time. Withdrawal of corticosteroids without tapering off can cause withdrawal symptoms, namely secondary adrenal insufficiency due to suppression of the hypothalamic-pituitary-adrenal (HPA) axis ${ }^{3,4}$. 
Adrenal insufficiency is a pathological condition characterized by decreased glucocorticoid production. Adrenal insufficiency is rare, with an incidence rate of $<0.01 \%$ in the general population. It can be classified as primary and secondary, with the latter occurring when exogenous steroids suppress the hypothalamic-pituitaryadrenal (HPA) axis, resulting in insufficient stimulation of the adrenal glands to secrete adrenocorticotropic hormone $(\mathrm{ACTH})^{5,6}$.

Case Report: A man aged 28 years came with complaints of weakness in both hands and feet for 3 days prior to hospital admission. Other complaints include fever $(+)$, nausea $(+)$, vomiting $(+)$, and decreased appetite. Bowel movement and bladder within normal limits. The patient was diagnosed with gout ( 3 years ago) and had since been routinely taking dexamethasone. In a day, the patient could take 9 to 15 tablets of dexamethasone until one month ago when the patient suddenly stopped.

Physical Examination 26 August 2020 (Upon arrival at the ER): The patient was generally weak; conscious (Compos mentis) with GCS 4-5-6; had blood pressure of $132 / 80 \mathrm{mmHg}$, pulse of $96 \times /$ minute, breathing of $22 \times /$ minute, and axillary temperature of $36.5{ }^{\circ} \mathrm{C}$. Other physical examinations revealed moon face $(+)$, buffalo hump $(+)$, and purplish $(+)$ striae on the abdomen. The acral extremities felt warm, and there was atrophy of the lower limb muscles, as well as oedema of both legs. Neurological examination revealed paraparesis with motor muscle strength of 2 for all extremities.

\section{Supporting Examination:}

Table 1. Hematological Examination.

\begin{tabular}{|c|c|c|c|c|c|c|}
\hline Parameter & $26-08$ & 27-08 & 28-08 & 31-08 & 02-09 & Normal range \\
\hline $\mathrm{Hb}(\mathrm{g} / \mathrm{dL})$ & 9.0 & 9.6 & 8.8 & 9.6 & 9.7 & $13.3-16.6$ \\
\hline $\operatorname{RBC}\left(10^{6} / \mathrm{uL}\right)$ & 3.36 & 3.66 & 3.33 & 3.81 & 3.65 & $3.69-5.46$ \\
\hline $\operatorname{HCT}(\%)$ & 26.4 & 38.3 & 27.4 & 30.4 & 29.4 & $41.3-52.1$ \\
\hline MCV (fL) & 84.7 & 81.5 & 82.3 & 79.8 & 80.5 & $86.7-102.3$ \\
\hline $\mathrm{MCH}(\mathrm{pg})$ & 26.6 & 26.2 & 26.4 & 25.2 & 26.6 & $27.1-32.4$ \\
\hline $\mathrm{MCHC}(\mathrm{g} / \mathrm{dL})$ & 34.1 & 33.9 & 32.1 & 31.6 & 33.0 & $29.7-33.1$ \\
\hline WBC $\left(10^{3} / \mathrm{uL}\right)$ & 11.22 & 9.84 & 9.68 & 12.73 & 13.5 & $4.1-11.0$ \\
\hline Eo $(\%)$ & 1.9 & 2.1 & 2.2 & 2.5 & 1.5 & $0.6-5.4$ \\
\hline Baso (\%) & 0.4 & 0.8 & 0.8 & 0.7 & 0.4 & $0.3-1.4$ \\
\hline Neut $(\%)$ & 82 & 70.3 & 59.3 & 69.1 & 86.6 & $39.8-70.5$ \\
\hline Lymph (\%) & 14.8 & 17.6 & 27.3 & 19.2 & 8.4 & $23.1-49.9$ \\
\hline Mono (\%) & 10.5 & 9.2 & 10.4 & 8.5 & 4.6 & $4.3-10$ \\
\hline PLT $\left(10^{3} / \mathrm{uL}\right)$ & 599 & 367 & 548 & 585 & 553 & $150-450$ \\
\hline RDW (\%) & 12 & 13.5 & 14.0 & 13.2 & 14.5 & $12.2-14.8$ \\
\hline $\operatorname{LED}(\mathrm{mm} / \mathrm{jam})$ & & & & & 52 & \\
\hline PPT (second) & 11.6 & 13.7 & & & & $9-12$ \\
\hline APTT pend.(detik) & 27.9 & 30.0 & & & & $23-33$ \\
\hline
\end{tabular}

Table 2. Clinical Chemistry Examination and Urinalysis.

\begin{tabular}{|l|c|c|c|c|c|c|c|}
\hline Parameter & $\mathbf{2 6 - 0 8}$ & $\mathbf{2 8 - 0 8}$ & $\mathbf{3 1 - 0 8}$ & $\mathbf{1 - 0 9}$ & $\mathbf{2 - 0 9}$ & $\mathbf{4 - 0 9}$ & Normal range \\
\hline $\mathrm{Na}(\mathrm{mmol} / \mathrm{L})$ & 137 & 137 & 137 & 138 & 136 & 143 & $136-145$ \\
\hline $\mathrm{K}(\mathrm{mmol} / \mathrm{L})$ & 2.3 & 3.4 & 3.4 & 2.9 & 3.4 & 3.1 & $3.5-5.1$ \\
\hline $\mathrm{Cl}(\mathrm{mmol} / \mathrm{L})$ & 98 & 98 & 104 & 100 & 99 & 103 & $98-107$ \\
\hline
\end{tabular}




\begin{tabular}{|c|c|c|c|c|c|c|c|}
\hline Parameter & 26-08 & 28-08 & 31-08 & 1-09 & 2-09 & 4-09 & Normal range \\
\hline $\mathrm{Ca}(\mathrm{mg} / \mathrm{dL})$ & & & & 6.8 & & & $8.5-10.1$ \\
\hline $\operatorname{Mg}(\mathrm{mg} / \mathrm{dL})$ & 0.8 & 1.2 & 1.4 & & 1.3 & 1.4 & $1.8-2.4$ \\
\hline BUN (mg/dL) & 4 & 2 & 9 & & & & $7-18$ \\
\hline $\mathrm{SC}(\mathrm{mg} / \mathrm{dL})$ & 1.2 & 1.2 & 0.9 & & & & $0.6-1.3$ \\
\hline Alb (g/dL) & 2.61 & 2.8 & 2.9 & & 3.0 & & $3.4-5$ \\
\hline GDA (mg/dL) & 67 & 90 & & & 109 & & $<200$ \\
\hline SGOT (U/L) & 56 & 59 & & & & & L: $0-50, P: 0-35$ \\
\hline SGPT (U/L) & 39 & 47 & & & & & L: $0-50, P: 0-35$ \\
\hline Chol (mg/dL) & & & & & & 240 & $0-200$ \\
\hline HDL (mg/dL) & & & & & & 44 & $40-60$ \\
\hline LDL (mg/dL) & & & & & & 164 & $0-90$ \\
\hline TG (mg/dL) & & & & & & 160 & $30-150$ \\
\hline CRP (mg/dL) & 13 & 14.67 & & & & & $0-1$ \\
\hline Cortisol (ng/mL) & & 18.67 & & & & $\begin{array}{c}19.58 \\
\text { (Dexamethasone } \\
\text { Suppression Test) }\end{array}$ & $\begin{array}{c}\text { Morning serum } \\
(08.00-10.00): 57.2-194.2 \\
\text { Afternoon serum } \\
\text { (16.00-18.00): } 20.2-131.0\end{array}$ \\
\hline ACTH $(\mathrm{pg} / \mathrm{mL})$ & & & & & 2.1 & & $7.4-64.3$ \\
\hline Urinalysis & $26-08$ & $28-08$ & $31-08$ & $1-09$ & $2-08$ & $4-08$ & Normal range \\
\hline $\mathrm{pH}$ & & 7.5 & & & & & \\
\hline Urine Kalium & & 27.75 & & & & & $35-80$ \\
\hline Urine Natrium & & 122.5 & & & & & $30-300$ \\
\hline Urine Chloride & & 145 & & & & & $85-170$ \\
\hline
\end{tabular}

Table 3. Blood Gas Analysis.

\begin{tabular}{|l|c|c|c|}
\hline Blood Gas Analysis & $\mathbf{2 6 - 0 8}$ & $\mathbf{2 8 - 0 8}$ & Normal range \\
\hline $\mathrm{pH}$ & 7.53 & 7.58 & $7.35-7.45$ \\
\hline $\mathrm{pCO}_{2}$ & 46 & 37 & $35-45$ \\
\hline $\mathrm{pO}_{2}$ & 76 & 81 & $80-100$ \\
\hline $\mathrm{HCO}_{3}$ & 36.4 & 34.7 & $22-26$ \\
\hline $\mathrm{TCO}_{2}$ & 39.8 & 24.5 & $23-30$ \\
\hline $\mathrm{BEecf}$ & 15.7 & 12.8 & $-3.5-2$ \\
\hline $\mathrm{SO}_{2}$ & $97 \%$ & $98 \%$ & $94-98$ \\
\hline $\mathrm{AaDO}$ & 16 & 3 & $15-50$ \\
\hline$\% \mathrm{FiO}$ & 21 & 21 & 37 \\
\hline $\mathrm{Temp}^{2}$ & 37 & & \\
\hline
\end{tabular}

Conclusion: The results of blood gas analysis on 26-08-2020 showed a metabolic alkalosis with compensation for respiratory acidosis. Blood gas analysis tests on 28-08-2020 revealed an uncompensated metabolic alkalosis. 
Table 4. Immunological Examination.

\begin{tabular}{|l|c|c|c|c|}
\hline Parameter & $\mathbf{2 8 - 0 8}$ & $\mathbf{3 0 - 0 8}$ & $\mathbf{3 1 - 0 8}$ & Normal range \\
\hline C3 & 42.7 & & & $50-12$ \\
\hline C4 & 24.0 & & & $17.4-52.2$ \\
\hline ANA Test & 10.82 & & & Neg $<40$, Pos $>=40$ \\
\hline FT4 & & 1.52 & 1.63 & $0,89-1.76$ \\
\hline TSH & & 1.993 & 1.863 & $>18$ y.0.: $0.55-4.78$ \\
\hline
\end{tabular}

Conclusion: Immunological and thyroid function examination results in the patient were within normal range.
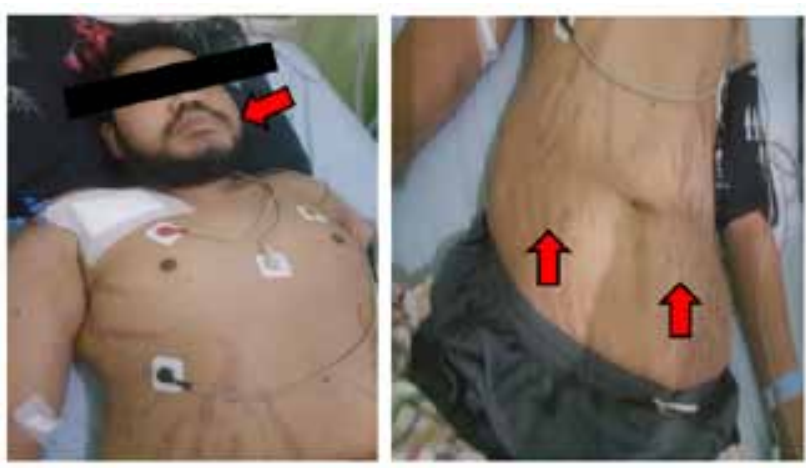

Figure 1. Moon face (left) and purplish striae on the abdomen (right).

\section{Discussion}

The adrenal glands, made up of the cortex and medulla, are located atop the kidneys. The adrenal gland cortex has 3 successive layers from the outside, namely the zona glomerulosa, the zona fasciculata and the reticular zone. These three layers secrete steroid hormones, namely mineralocorticoids produced by the zona glomerulosa, and glucocorticoids and androgens secreted by the zona fasciculata and the zona reticularis. Cortisol is the main product of glucocorticoids, which plays a role in regulating the metabolism of carbohydrates, proteins, and fats ${ }^{7,8}$.

Cortisol secretion is controlled by corticotropin or adrenocorticotropic hormone (ACTH), which is secreted by the anterior pituitary, further regulated by hypothalamic hormones to secrete corticotropin (CRH). Both ACTH and CRH are controlled by cortisol via a feedback mechanism ${ }^{2,7}$.
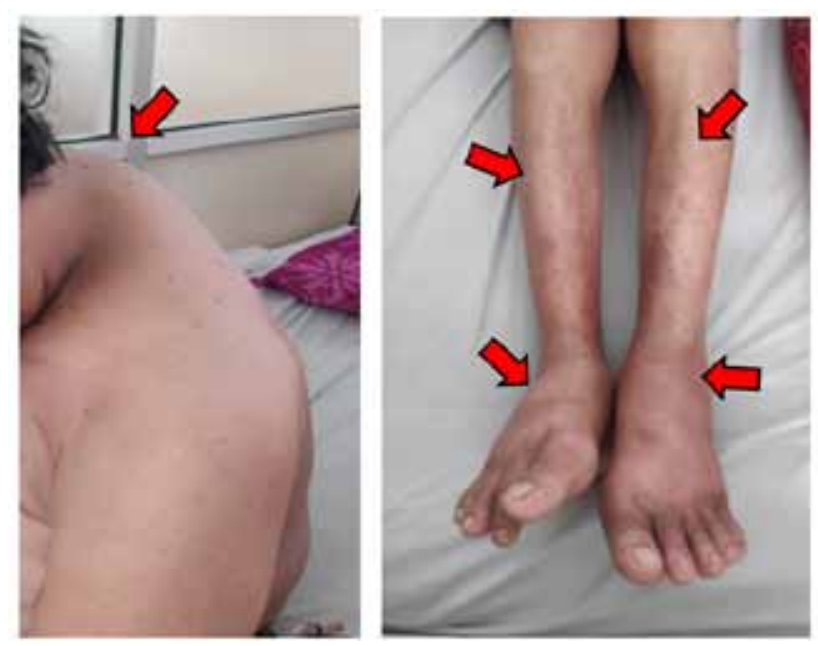

Figure 2. Buffalo hump (left) and atrophy of the lower limbs with edema in the instep (right).

Glucocorticoids work as catabolic hormones, causing the breakdown of protein and fat and inhibiting protein synthesis in muscle, connective tissue, fat tissue, and lymphoid cells. This hormone also has an anabolic effect on metabolism in the liver ${ }^{2,7,8}$.

This patient presented with complaints of weakness and fatigue. On examination, purplish striae in the armpits and lower abdomen was found. The breakdown of protein causes muscles to weaken, bone structure to thin, and lessens the skin's resistance. Stretch of the skin over the site of new fat deposition added with loss of elasticity due to protein catabolism results in rupture of blood vessels' surface. Blood seeps through the gaps caused by collagen catabolism so that purple striae can be observed ${ }^{7}$.

The patient has hyperlipidemia characterized by increased levels of total cholesterol $240 \mathrm{~g} / \mathrm{dL}$, triglycerides $160 \mathrm{~g} / \mathrm{dL}$, high-density-lipoprotein (HDL)- 
cholesterol: $44 \mathrm{mg} / \mathrm{dL}$, and low-density-lipoprotein (LDL)-cholesterol: $164 \mathrm{mg} / \mathrm{dL}$. Hyperlipidemia occurs due to cortisol's potentiating effect on other hormones such as somatotropins and catecholamines in the lipolysis process in fat tissue $e^{3,6,8}$.

Hypercortisolism causes accumulation of fatty tissue in particular places such as the face (moon face), the interscapular area (buffalo hump) and the mesenteric base (body obesity). The cause of this characteristic distribution of fatty tissue is unknown, but it is thought to be related to insulin resistance and/or elevated insulin levels ${ }^{3,7}$. As the case showed, this patient had moon face, buffalo hump and body obesity.

Additionally, he has hypertension, which, in patients with Cushing's syndrome, occurs due to increased production of angiotensin II as a result of increased hepatic production of angiotensinogen, increased activity of blood vessels against vasoconstrictive hormones, decreased reuptake of catecholamine degradation products, or inhibition of vasodilators such as kinins and prostaglandins 9 .

Sudden discontinuation of corticosteroid use without tapering off can cause withdrawal symptoms such as secondary adrenal insufficiency due to suppression of the hypothalamic-pituitary-adrenal (HPA) axis ${ }^{5,10}$. Steroid withdrawal syndrome is a syndrome with symptoms of lethargy, malaise, anorexia, myalgia, headaches, fever, and skin desquamation. Sufferers have symptoms of weakness, fatigue, anorexia, nausea, and vomiting, all of which are present in the patient.

The diagnosis of exogenous Cushing's syndrome begins with clinical suspicion based on a physical examination. Exogenous Cushing's syndrome is indicated by low serum cortisol levels in the morning. ACTH levels are also relatively low since ACTH production by the pituitary is suppressed by exogenous steroids $^{3}$.

Secondary adrenal insufficiency caused by ACTH deficiency is commonly caused by exogenous glucocorticoid therapy ${ }^{3,5}$. This patient had a history of long-term dexamethasone use in high doses. Taking dexamethasone will result in high levels of cortisol in the blood which in turn will reduce the secretion of ACTH.

Diagnosis of adrenal insufficiency is based on the suspicion of the patient's symptoms, clinical chemistry examination, and serum ACTH and serum cortisol levels ${ }^{11}$. In secondary adrenal insufficiency, ACTH suppression has minimal effect on aldosterone secretion by the zona glomerulosa, therefore, there is no manifestation of mineralocorticoid deficiency. Hyponatremia and hyperkalemia rarely occur due to the reasons above ${ }^{4,5}$. The patient experienced low intake and vomiting which causes low potassium and magnesium levels, resulting in complaints of weakness in the 4 extremities. The weakness ameliorated after therapy and gradually improved as the patient's potassium and magnesium levels improved.

The next step after clinical suspicion of Cushing's syndrome is to prove that there is excess secretion of the hormone cortisol and impaired feedback mechanism of the hypothalamic-pituitary-adrenal axis. For initial laboratory testing, many guidelines recommend one of the following tests: two 24-hour urine-free cortisol checks, late night salivary cortisol, $1 \mathrm{mg}$ overnight dexamethasone suppression test or a longer dose dexamethasone suppression test. These three tests are the most common types of initial tests to evaluate the possibility of Cushing's syndrome. They are often faced with difficulty or entirely not available in developing countries, so, pragmatically, only morning cortisol levels are checked. For morning serum cortisol, the results are quite acceptable if the results are extremely high.

Patient's history and physical examination strongly supported the diagnosis of Cushing's syndrome, but the laboratory examination did not show an increase in serum cortisol levels. The patient had a decreased level of cortisol (serum $08.00 \mathrm{am}$ ), namely $18.67 \mathrm{ng} /$ $\mathrm{mL}$. Morning serum cortisol levels indicate adrenal insufficiency caused by corticosteroid therapy when levels are below $<3 \mu \mathrm{g} / \mathrm{dL}(<30 \mathrm{ng} / \mathrm{mL})$ and indicate normal adrenal function when values are $>20 \mu \mathrm{g} / \mathrm{dL}$ $(>200 \mathrm{ng} / \mathrm{mL})^{3,4}$.

Serum ACTH levels are used to differentiate primary and secondary adrenal insufficiency. Ideally, an ACTH stimulation test using synthetic ACTH $\left(\right.$ Cortrosina ${ }^{\circledR}$, Synacthen ${ }^{\circledR}$ ) is carried out by first determining the baseline serum cortisol level, then injecting $250 \mathrm{mcg}$ of ACTH intravenously, followed by assessing the serum cortisol level 30 and 60 minutes after ACTH administration. Normally, after an ACTH stimulation test there will be an increase in serum cortisol levels $>20$ $\mathrm{mcg} / \mathrm{dL}$ or an increase of $>10 \mathrm{mcg} / \mathrm{dL}$ from the patient's initial cortisol level (baseline). In secondary adrenal insufficiency, there is no increase in serum cortisol 
levels after the ACTH stimulation test ${ }^{4,6}$. The limitation in this case was that the ACTH stimulation test was not performed because no synthetic ACTH was available in the Pharmacy Unit of Dr. Soetomo Hospital Surabaya.

In the presence of secondary adrenal insufficiency, serum ACTH levels are low $(<5 \mathrm{pg} / \mathrm{mL}[1.10 \mathrm{pmol} / \mathrm{L}])$. The patient had a decreased serum ACTH level, namely $2.1 \mathrm{pg} / \mathrm{mL}^{12}$. This supported the diagnosis of secondary adrenal insufficiency.

\section{Conclusion}

The patient was diagnosed with exogenous Cushing's syndrome based on a history of long-term use of dexamethasone. Physical examination revealed moon face, buffalo hump, purplish striae, and hypertension. Sudden discontinuation of dexamethasone causes withdrawal symptoms, one of which being secondary adrenal insufficiency as evidenced by low morning serum values for cortisol and ACTH parameters.

Conflict of Interest: The author declare that they have no conflict of interest.

Source of Funding: This study supported by the Universitas Airlangga through the Annual Budget Activity Plan 2018.

Acknowledgements: We would like to thank the participants who have voluntarily participated, the Ponorogo Government Regency that support this study and the enumerators who have collected data. We additionally thank Arif Nur Muhammad Ansori for editing the manuscript.

Ethical Approval: This study approved by the Ethics Committee from Faculty of Public Health, Universitas Airlangga (121-KEPK/2018).

\section{References}

1. Guaraldi F, Salvatori R. Cushing syndrome : Maybe not so uncommon of an endocrine disease. 2012; 199-208.

2. Siddiqi AI, Usamah M, Noor B. Review article diagnosis of Cushing's syndrome: Biochemical Investigations. 2017; 3(4).

3. Hopkins RL, Leinung MC. Exogenous Cushing's syndrome and glucocorticoid withdrawal. 2005; 34: 371-84.

4. Alves C, Cristina T, Robazzi V, et al. Withdrawal from glucocorticosteroid therapy : clinical practice recommendations. 2008; 84(3): 192-202.

5. Younes AK, Younes NK. Recovery of steroid induced adrenal insufficiency. Transl Pediatr. 2017; 6(1): 269-73.

6. Igaz $\mathrm{P}$, Rácz $\mathrm{K}$, Tóth $\mathrm{M}$, et al. Treatment of Iatrogenic Cushing's Syndrome. 2007; 1(1): 63-72.

7. Kirk Jr, L.F., Hash, R.B., et al. Cushing's Disease: Clinical Manifestations and Diagnostic Evaluation. . Am Fam Physiciancan. 2005; 62.

8. Hernaningsih Y, Soehita S. Sindroma Cushing Pada Kehamilan. Clin Pathol Med Lab. 2005; 12(1): 21-30.

9. Harris GD FG. Hypertensive Endocrine Disorders. Clinics in Family Practice. 2002; 4(3).

10. Stewart PM N-PJ. The adrenal cortex. In: Melmed S, Polonsky KS, Larsen PR, Kronenberg HM, eds. Williams Textbook of Endocrinology. 13th edPhiladelphia, PA: Elsevier; 2016: 490-555.

11. Nimkarn S. Endocrinology Metabolism Adrenal Insufficiency Overview. 2017; 1-11.

12. Grossman AB. Secondary Adrenal Insufficiency. Endocr Metab Disord - MSD Man Prof Ed. 2020; 2-3. 